\title{
Huella y sombra de la violencia en la Universidad Autónoma Benito Juárez de Oaxaca
}

\section{Mark and a shadow of violence in the University Autonomous Benito Juarez of Oaxaca}

\author{
Santos Noé Herrera Mijangos \\ Jorge Gonzalo Escobar Torres \\ Javier Moreno Tapia \\ Flor de María Erari Gil Bernal \\ María Edith Gómez Gamero \\ Universidad Autónoma del Estado de Hidalgo
}

\section{Resumen}

En el presente artículo se muestra la violencia y las secuelas que sufren algunos docentes e investigadores de la Universidad Autónoma Benito Juárez de Oaxaca (UABJO). La institución educativa es una caja de resonancia de la sociedad y el contexto internacional marcados por los crecientes índices de pobreza, exclusión y marginación, así como por la política del Estado de análisis. Para conocer la violencia y el sufrimiento que se vive en la UABJO, se recurrió a un método mixto. Desde la perspectiva cualitativa se manejó la metodología inductiva-analítica a partir de una visión situacional (aquí y ahora) y un enfoque histórico para conocer su historia. De la parte cuantitativa, se aplicó un cuestionario en diversas facultades de la universidad para así sustentar o desechar nuestra inferencia sobre el sufrimiento como la sombra de la violencia. Es pertinente mencionar que con base en los resultados, que la violencia y el sufrimiento en la UABJO, lejos de que decrezcan, se incrementarán exponencialmente hasta alcanzar niveles insospechados, y, lo que es peor, la sociedad oaxaqueña comienza a acostumbrarse a sufrir y convivir con esta problemática.

Palabras clave: violencia, sufrimiento, universidades, docentes, investigadores.

Nota del autor

Santos Noé Herrera Mijangos, Departamento de Psicología, Universidad Autónoma del Estado de Hidalgo (UAEH); Jorge Gonzalo Escobar Torres, Departamento de Psicología, UAEH; Javier Moreno Tapia, Departamento de Psicología, UAEH; Flor de María Erari Gil Bernal, Departamento de Psicología, UAEH; María Edith Gómez Gamero, Departamento de Psicología, UAEH.

La correspondencia en relación con este artículo debe dirigirse Santos Noé Herrera Mijangos, Departamento de Psicología, UAEH, calle deportiva número 9, colonia Progreso, C. P. 42980, Atotonilco de Tula, Hidalgo, México.

Dirección electrónica: psicologonoe@yahoo.com.mx 


\begin{abstract}
This article shows violence and the consequences suffered by some teachers and researchers from the University Autonomous Benito Juarez of Oaxaca (UABJO). The school is a soundboard of society, the international context, marked by rising rates of poverty, exclusion and marginalization, as well as state policy. To know the violence and suffering that exists in the UABJO, we used a mixed method. In the qualitative approach, the inductive-analytical methodology was handled. We care about the situational approach (here and now) and a historical approach to understand their history. In the quantitative part, a questionnaire was applied in various faculties of the university in order to support or reject our inference that suffering is the shadow of violence. It is pertinent to mention that based on our results, violence and suffering in the UABJO will exponentially increase, and the worst is that, Oaxacan society is becoming accustomed to suffer and live with this problem.
\end{abstract}

Keywords: violence, suffering, universities, teachers, researchers.

Este artículo presenta los resultados de una investigación que se realizó en la UABJO durante 2014. Una institución educativa que, como caja de resonancia, manifiesta parte de la cultura política y social de su Estado. Hay dos dichos que durante el levantamiento del trabajo de campo fueron registrados constantemente y reflejan una porción de la cultura de los sujetos de análisis: "Los oaxaqueños todo lo enredan, hasta el queso" y "Para todo mal mezcal y para todo bien también". Después de hacer el análisis de esta investigación, se consideró que las frases son una guía para entender la idiosincrasia de la institución y sus actores.

El trabajo está dividido en seis apartados: 1. El encuadre teórico presenta a los autores que muestran y apoyan nuestra visión de huella ecológica, la cual utilizamos como un símil en el vestigio y sombra de la violencia; 2. En la sección de método se delimitó el fenómeno de análisis y las estrategias que seguimos en el trabajo empírico; 3. El apartado, "Afuera y adentro: huella de la violencia en los murales y la cotidianidad", permite conocer mediante el análisis de dos murales la historia que vivieron los oaxaqueños en el 2007, así como las coincidencias de nuestros encuestados; 4. El apartado, "Sufrimiento como sombra de la violencia", se adentra en las entrañas de la institución y muestra las vicisitudes que provocan malestar y sufrimiento a los docentes e investigadores; 5. El quinto punto de este artículo muestra las secuelas que presentan algunos profesores por la violencia y sufrimiento que han padecido en la institución educativa; y 6. La última unidad se empleó para verter las conclusiones y coincidencias del artículo.

En el marco de la presente investigación resulta relevante mencionar la vinculación que guarda con otras similares que se han realizado en diversas universidades de México (Universidad Autónoma del Estado de México, Universidad Michoacana de San Nicolás de Hidalgo, Universidad Autónoma Metropolitana, entre otras; véase también Herrera, 2014, julio 2014, septiembre 2014 y octubre 2014) y Sudamérica (Colombia: Universidad de Medellín y Universidad de Antioquia), ya que la finalidad a largo 
plazo es validar un cuestionario y tener el pulso (cualitativo y cuantitativo) del estado biológico, psicológico y social de docentes e investigadores en las universidades latinoamericanas.

Encuadre teórico: huella ecológica, huella y sombra de la violencia

Desde hace 33 años, William Rees ha enseñado el significado de huella ecológica, que de igual manera ha sido desarrollado por Mathis Wackernagel y otros estudiantes en la brigada para Comunidades Sanas y Sustentables de la Universidad de British Columbia. Con respecto al concepto, Wackernagel y Rees (2001) comentan:

Piense en una economía como un organismo con un $<$ metabolismo industrial $>$. En este aspecto se puede comparar a una vaca en una pradera. La economía requiere <comer $>$ recursos y eventualmente toda esta ingestión se transforma en desechos y debe salir del organismo (la economía) de nuevo. (p. 29).

En dicho sentido, el organismo necesita recursos para subsistir y un espacio para desechar sus desperdicios. Al dar forma a ese organismo podemos tomar como referencia a cualquier ser humano. Imaginemos la extensión de tierra que se necesita para cultivar todos sus alimentos, para obtener los productos de origen animal, para producir la energía que consume como luz, gasolina, gas, entre otros. Ahora imaginemos la extensión de tierra que se requiere para absorber sus desechos. Si honestamente se pone en una balanza la huella ecológica de muchos seres humanos, sería muy claro que se consume y contamina más de lo que se necesita y se produce. A lo que puede agregarse que así como la vaca aporta leche y carne para el equilibrio ecológico, ¿qué se aporta de forma independiente? Y esto no se refiere sólo a lo material, porque también se involucra la parte social, cultural y espiritual. Hay algo claro para los ambientalistas: el planeta empieza a resentir los abusos ecológicos de la humanidad y de alguna u otra manera somos responsables del déficit en la ecología.

La violencia y la huella ecológica tienen algo en común, la gran mayoría de los seres humanos contribuye para que exista un déficit en el medio ambiente ecológico y social (Wackernagel \& Rees, 2001). En la cotidianidad, estamos inmersos en un mundo donde la violencia es un lubricante de las relaciones sociales, basta con hojear cualquier periódico del orbe o escuchar las noticias de los medios masivos de comunicación. Ahora, si reflexionamos sobre nuestras actividades cotidianas con base con un paralelo y con la huella ecológica, sería fácil descubrir que, en gran medida, aportamos de una u otra manera a la violencia que se vive en nuestro alrededor. Durante el día recibimos fuertes dosis de violencia que procesamos y regresamos al mundo exterior. Aunque, claro está, la responsabilidad no recae solamente en los sujetos, el sistema capitalista aporta de manera significativa a la violencia. Una investigadora de la Universidad Autónoma del Estado de Nuevo León comenta al respecto:

El sistema capitalista es violencia pura, es un sistema que destruye para poder crecer. La violencia está insertada en la lógica del sistema. Para que una empresa pueda crecer tiene que eliminar a otras empresas. La 
competencia no es así como se dice: la sana competencia, medir las fuerzas. Es sacar al otro del mercado. Significa destruir su base de producción a través de ofrecer la mercancía más barata. (S., comunicación personal, 29 de agosto de 2013).

En concordancia con la entrevistada, se infiere que las reglas del sistema capitalista generan un juego de competencia en la sociedad e incitan a eliminar al otro, a aquel que interfiera en el mismo mercado. El Estado, regulador de la sociedad, avala y justifica la competencia entre sus ciudadanos, y cuando no hay entendimiento entre el pueblo interviene violentamente mediante sus instituciones con resultados fulminantes para aquellos que perturban el sistema.

En cuanto al encuadre teórico de la violencia, la palabra proviene del latín: vis (fuerza). Blair (2009) sostiene que no hay una definición conceptual como tal, sólo aproximaciones, "quizá porque no existe una teoría capaz de explicar todas las formas de violencia" (p. 10), es decir, la violencia física, psicológica, social, simbólica, de género, entre otras. Además, “a quien habla de violencia hay que preguntarle siempre qué entiende por ella" (Blair, 2009, p. 10). Si aceptamos la postura de Blair, puede agregarse que inclusive los grandes teóricos difieren en su postura en cuanto al concepto de violencia.

En México se ha documentado la violencia que se vive en las instituciones educativas (Herrera, 2009, 2014c; Herrera \& Navarrete, 2013). Se diría que éstas son espacios de armonía, aunque en realidad existe una violencia de estados alarmantes. Al respecto, Ball (1994) comenta: “Considero las escuelas, al igual que prácticamente todas las otras organizaciones sociales, campos de lucha, divididas por conflictos en curso o potenciales entre sus miembros, pobremente coordinadas e ideológicamente diversas" (p. 35). En coincidencia con Ball, en los siguientes apartados se mostrará que los conflictos pueden deberse a la lucha del poder (rectoría, direcciones, jefaturas, etc.), recursos humanos (estudiantes, profesores, etc.), materiales (salones, cubículos, etc.) y económicos (becas, estímulos de desempeño, etc.), entre otras múltiples variables. Aunque se sabe que la tarea primaria de las instituciones educativas es educar, comúnmente están inmersas en conflictos que padecen interna o externamente, ya que la institución educativa es una caja de resonancia de la sociedad lubricada por la violencia.

Al asumir la responsabilidad que implica ofrecer un concepto sobre violencia, así como al aceptar que éste puede ser debatible desde diferentes posturas empíricas y teóricas, en este artículo la propuesta se respalda en los resultados del trabajo empírico y la visión de los diversos teóricos que presentamos. Para sustentar esta postura, concordamos con Uribe (2012) en cuanto a que "la violencia tendrá que ser analizada, considerando otros elementos y no solo partiendo de ella misma" (p. 56). En esta investigación se analizan tres elementos de la violencia: la historia (¿dónde, cuándo?), el propósito (¿para qué?, ¿quién la ejerce y la recibe?) y las consecuencias (impunidad, conflicto y sufrimiento). 
Para abonar a este concepto, coincidimos con Velázquez (2011), quien dice que es pertinente "diferenciar entre violencia contra la escuela y violencia dentro de la escuela... Así como de dentro hacia fuera" (p. 17). En este caso, cuando hablamos: de afuera hacia adentro de la escuela, nos referimos a la violencia que ejercen actores externos de la sociedad, por ejemplo, los medios masivos de comunicación y el Estado, particularmente con sus recortes presupuestales, la imposición de secretarios de educación-rectores o directores_- intervención militar — Tlatelolco, 1968 y Ayotzinapa, Guerrero, 2014 , etc. Con respecto a la violencia: de adentro hacia afuera de la escuela, traemos a escena, por ejemplo, las manifestaciones de los profesores y estudiantes, que si bien podrían tener un sustento justo, también ocasionan daños colaterales a los mismos integrantes de la institución y sociedad. Finalmente, al describir la violencia: dentro de la escuela, nos referimos a la violencia física, psicológica, social, simbólica, de género, escolar (mobbing y bullying), al acoso laboral, entre otras. Para los propósitos del estudio centramos la violencia en las instituciones educativas. Definimos y acotamos que la violencia en las instituciones educativas tiene una historia, propósito y consecuencias; por lo común, la encontramos dentro y fuera de sus fronteras, pero principalmente entre sus actores institucionales, quienes buscan sin cansancio su propio bienestar antes que el bien colectivo.

Por otra parte, el sufrimiento humano no ha sido conceptualizado con amplitud en la psiquiatría ni la psicología. Aunque parezca in- creíble, el Manual Diagnóstico y Estadístico de los Trastornos Mentales (DSM, siglas en inglés), no contempla el sufrimiento en sus clasificaciones y en la psicología no existe un teórico respetable que formule un concepto congruente. $\mathrm{La}$ palabra sufrimiento proviene del latín sufferre y tiene tres definiciones: 1) padecimiento, dolor, pena; 2) hecho de sentir físicamente un daño; y 3) sufrir o padecer dolor físico o moral (Moliner, 1998; Real Academia Española, 2001). Los sinónimos que utilizamos son tolerancia, padecimiento, pena, dolor, angustia, daño, mal, tortura, dolencia, malestar, achaque, trago (Espasa Calpe, 1994).

Por nuestra parte, apoyamos la postura de Gampel (2006), quien considera el sufrimiento como incuantificable. Los seres humanos no sufrimos por lo mismo, aunque hay sufrimientos que pueden ser homogéneos, por ejemplo: la enfermedad, la muerte de un ser querido y la presión social. Para los propósitos de este artículo, se dividió el sufrimiento en dos dimensiones y cuatro áreas. En cuanto a las dimensiones: la manifiesta, parece y puede ser descrita a partir de la observación directa, en tanto la latente permanece oculta o negada y se infiere a partir de la interpretación. Con respecto a las áreas, las investigaciones (Herrera, 2002, 2005, 2008, 2009; Herrera \& Navarrete, 2013), muestran que la sociedad y sus instituciones causan malestar a sus colaboradores en cuatro áreas: 1) psíquico (personal); 2) social (demandas de la postmodernidad); 3) profesional (relativo a la profesión); y 4) institucional (vida cotidiana en el área de trabajo). 
A continuación se presenta la metodología de trabajo e, inmediatamente después, parte de la violencia que ha vivido la UABJO (de afuera hacia adentro, de adentro hacia afuera y dentro de ella).

\section{Método}

Para esta investigación se utilizó un método mixto. En el enfoque cualitativo, se manejó la metodología inductiva-analítica, que no pretende evaluar modelos, hipótesis o teorías, sino ir de cuestionamientos generales a otras interrogantes que se adhieren en el transcurso de la investigación. El método permitió trabajar en el mundo empírico y no abordó a los actores institucionales como variables, por el contrario, se interesó por su biografía e interpretación de su realidad. El objetivo principal de la investigación fue tener una visión global del estado biopsicosocial que viven los docentes e investigadores de la UABJO.

El trabajo cualitativo que se realizó del 9 al 13 de diciembre de 2013 fue el siguiente: 1 . Etnografía de los espacios. Se tomaron más de 200 fotografías; 2. Observación participante. Se asistió a reuniones del sindicato y celebraciones sociales que permitieron observar la interacción entre los sujetos de análisis; y 3. Se realizaron entrevistas a profundidad y focales a 17 sujetos clave de seis diferentes facultades.

Para la elaboración del cuestionario, se consideró el trabajo cualitativo realizado en la primera fase de la investigación. Se tomaron en cuenta tres aspectos: 1. Bibliografía relacionada con el objeto de análisis e investigaciones previas; 2. Entrevistas a especialistas del área, profesores e investigadores; y 3. Documentos institucionales (información relevante de la universidad) y etnográficos (material que se recopiló durante el trabajo empírico). Una vez elaborado el instrumento de medición, se piloteó en la Universidad Autónoma del Estado de México y con los resultados obtenidos se ajustó el cuestionario para aplicarlo en la UABJO. La encuesta se realizó del 29 abril al 2 de mayo de 2014. Además, tuvo una muestra de 59 sujetos de nueve facultades (Administración, Bellas Artes, Ciencias de la Educación, Derecho, Idiomas, Odontología, Química, Sociología y Veterinaria), ubicadas en la Ciudad Universitaria de la UABJO.

\section{Resultados}

\section{Afuera y adentro: huella de la violencia en los murales y la cotidianidad}

Con base en lo dicho por Velázquez (2011), en este apartado se presenta la violencia de afuera hacia adentro de la escuela, así como dentro de la misma. En una primera parte, se expone el trabajo etnográfico (fotografías) que permite conocer un periodo de la historia de la institución, posteriormente, se muestra desde el enfoque cuantitativo una figura que devela la violencia hacia y dentro de la UABJO. Es pertinente subrayar que la pretensión de este análisis etnográfico no es analizar el conflicto ni las causas del mismo, solamente se examina la violencia de las imágenes, sobre todo, se evidencia la 
poca importancia que se le otorga a los murales por ser algo tan cotidiano para la comunidad oaxaqueña.

Las fotos de los murales que se mostrarán a continuación fueron tomadas en la $\mathrm{UABJO}$, en ellas se ilustran murales plasmados en las bardas que están sobre la avenida principal de Ciudad Universitaria, precisamente, a la altura del Instituto de Ciencias de la Educación, al final del complejo de facultades. Éstos representan el conflicto oaxaqueño acaecido en 2007 y encabezado por la Asamblea Popular de Pueblos de Oaxaca (APPO). Dado que carecen de título, fueron nombrados mural uno: Conflicto: Estado vs. Pueblo (figura 1) y mural dos: Nunca olvidamos, nunca perdonamos (figura 2). Cabe destacar que solamente en el primer mural aparece el nombre Balam y desconocemos si es el autor.
Para contextualizar las expresiones artísticas y el conflicto damos voz a Bautista (2008), quien dice:

El conflicto alcanzó uno de sus puntos de activación la madrugada del 14 de junio de 2007, cuando una concentración de profesores de la sección 22 del Sindicato Nacional de Trabajadores de la Educación (SNTE), que pugnaba por una serie de reivindicaciones laborales, fue agredida por la policía estatal en el zócalo de la ciudad de Oaxaca. Como consecuencia de la represión, más de 300 organizaciones se solidarizaron con el gremio y se formó la APPO, quien asumió como principal demanda la salida del gobernador Ulises Ruiz Ortiz. (p. 37).

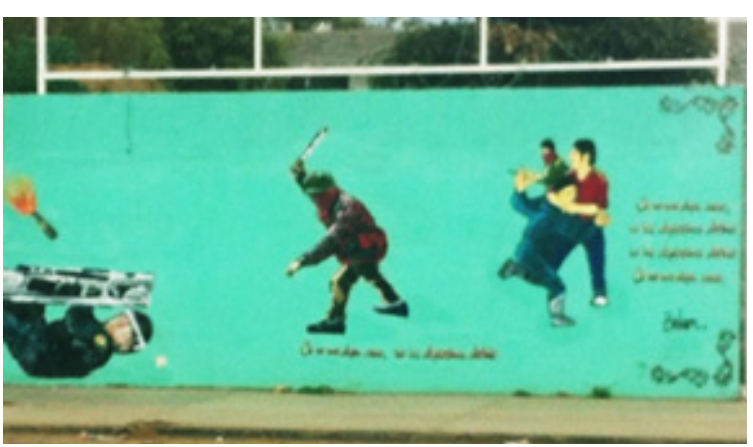

Figura 1. Mural uno. Conflicto: Estado vs. Pueblo.

Lo sorprendente del mural uno es la violencia radical de las posturas representadas. Por un lado, se observa a un policía uniformado con vestimenta antimotines que intenta golpear con un tolete a un infante descalzo, indefenso y llorando. Al lado podemos ver a una mujer joven vestida con ropa típica de la región; en ella se puede apreciar una leve sonrisa. En su mano derecha carga un machete y en la otra extremidad la cabeza de una persona muy parecida al que fuera gobernador del estado de Oaxaca en el sexenio 2004-2010. 
En la parte derecha del mural se observa a un policía tirado en el piso, protegiéndose de una bomba molotov y de un probable ataque del sujeto que está al lado. Dicho sujeto se encuentra con el rostro cubierto, vestimenta típica de la guerrilla y en su mano derecha sostiene un machete. A su costado se posicionan otros dos sujetos., uno de ellos viste similar a su compañero y el otro tiene agarrado por el cuello a un policía. Hay unas palabras escritas al final del mural que a la letra dicen: "Si no nos dejan soñar, no los dejaremos dormir". Tal expresión manifiesta la historia del conflicto, así como una amenaza radical a favor de la confrontación.

Hacia la izquierda de la misma avenida, en la siguiente barda de la UABJO, se puede observar el mural dos: Nunca olvidamos, nunca perdonamos, que evidencia el sentir de los manifestantes. La expresión refleja el deseo de mantener en la memoria colectiva los "23 asesinatos ocurridos durante el movimiento y los excesos desplegados por los cuerpos policiacos y paramilitares" (Bautista, 2008, p. 42), así como el resentimiento por diversas acciones del Estado.

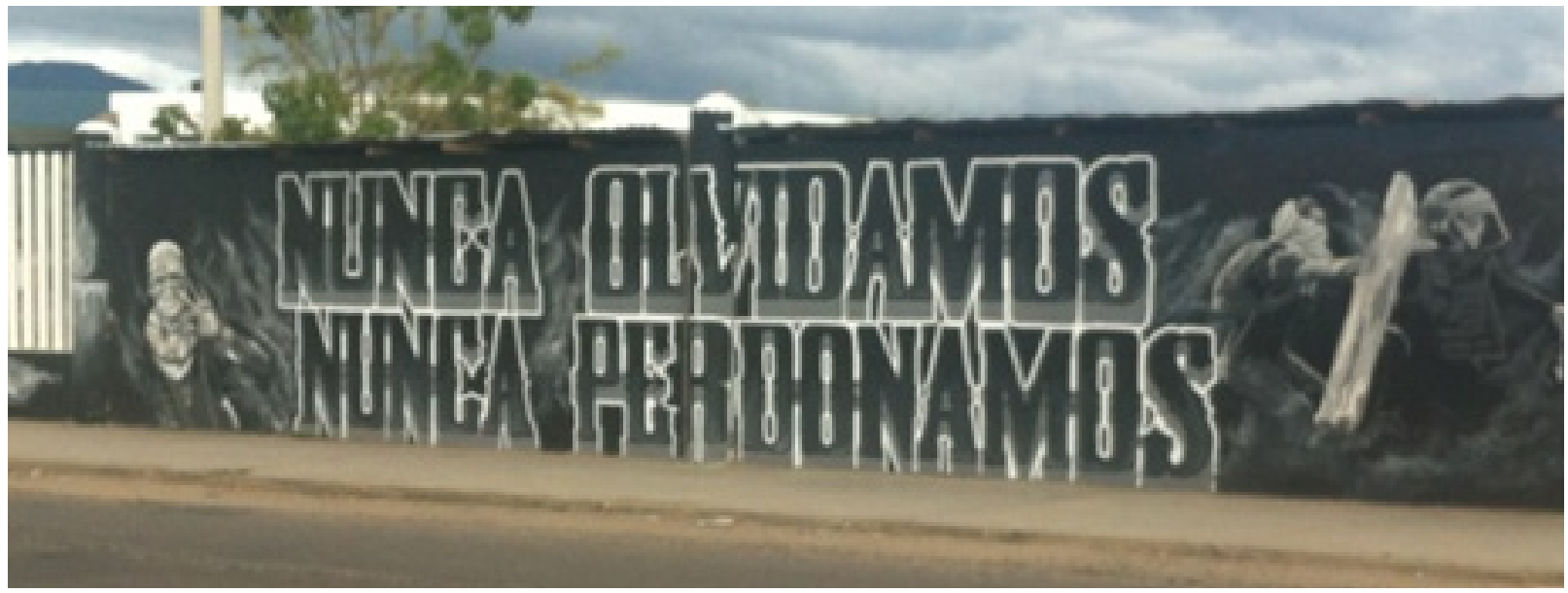

Figura 2. Mural dos. Nunca olvidamos, nunca perdonamos.

La expresión del mural manifiesta que los involucrados en el conflicto no están dispuestos a olvidar y perdonar. Cabe destacar que según Bautista (2008):

El informe de la Comisión Civil Internacional de Observación de los Derechos Humanos consideró que el conflicto del estado fue social, no sólo magisterial, y que los hechos ocurridos en Oaxaca son un eslabón de una estrategia jurídica, policiaca y militar, con componentes psicosociales y comunitarios cuyo objetivo último es lograr el control y amedrentamiento de la población civil en zonas donde se desarrollan procesos de organización ciudadana o movimientos de carácter social no partidista. (p. 43). 
Los dos murales manifiestan una violencia que se generó fuera de la UABJO en el 2007, pero al ser la universidad una caja de resonancia de la sociedad, en la actualidad hacia y dentro de la institución se vive una violencia similar a los acontecimientos presentados en los murales. Para conocer el contexto de la UABJO, se aplicó una encuesta que cuestionó a los sujetos de análisis sobre la vida académica externa e interna de su universidad. Los resultados que reveló la encuesta, reproducidos en la figura 3, coinciden con lo que expresaron los entrevistados. En cuanto a los factores externos, $81.35 \%$ indicó que la vida académica de la universidad se ve afectada por la inseguridad, narcotráfico, pobreza y marchas, entre otras variables. Se puede constatar que tanto la política del Estado e intromisión de los políticos (72.88 \%) también afectan y violentan la vida institucional de la universidad.

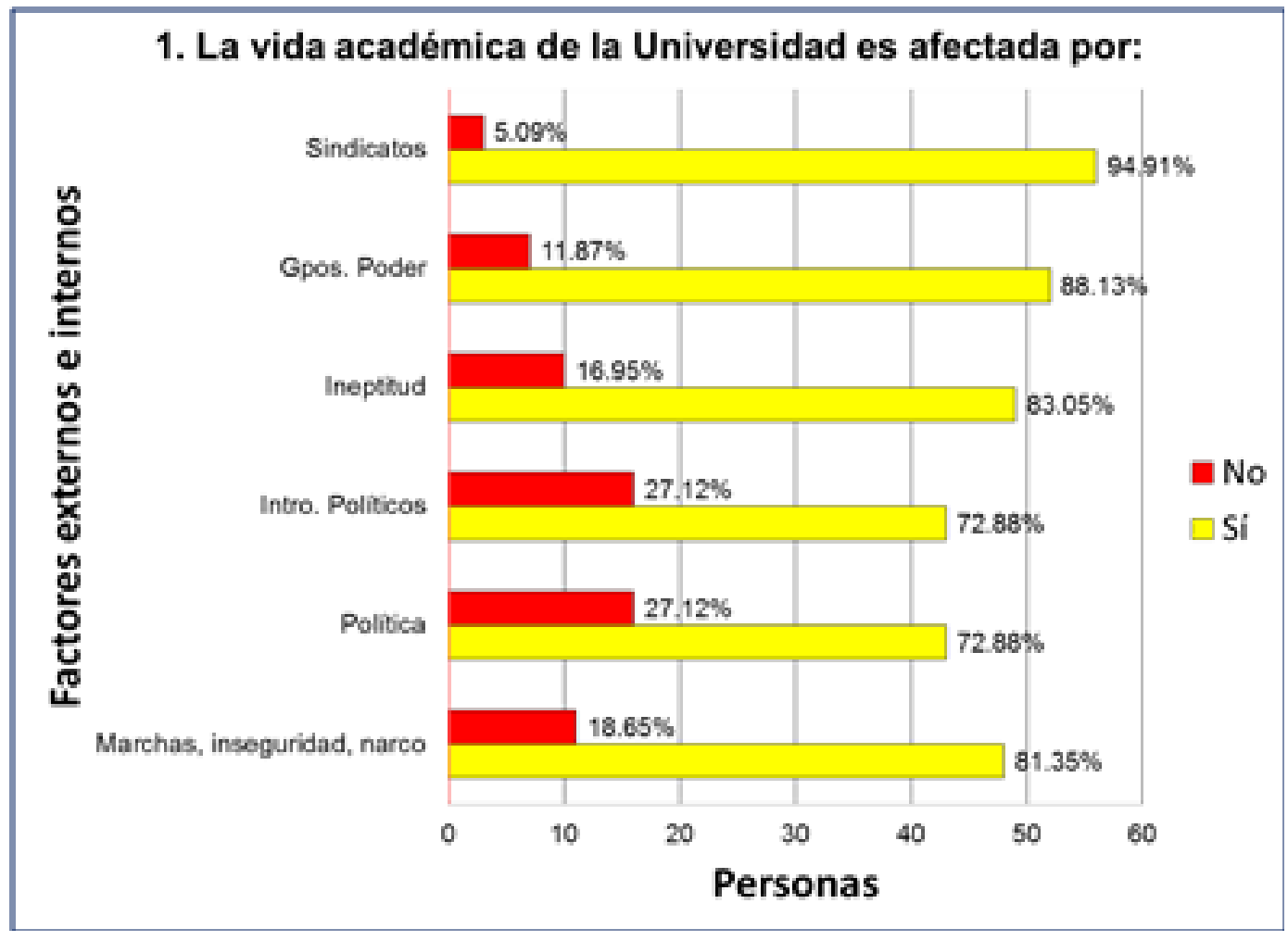

Figura 3. Resultados de la encuesta sobre los factores internos y externos que influyen en la vida académica.

En cuanto a los factores internos, los encuestados marcaron, con $94.92 \%$, que el sindicato es el actor que más afecta la vida académica, así como los grupos del poder $(88.13$
$\%)$, constantemente en conflicto. Es prudente mencionar que los sujetos de análisis consideran que la ineptitud de sus autoridades (83.05\%), designadas por cuestiones políticas, de igual 
manera afecta en gran medida la vida académica de la UABJO, es decir, estas variables impiden que se realice eficientemente la tarea primaria de la institución porque está "influenciada por la ideología de la organización, por la violencia y sufrimiento que se padece interna o externamente" (Herrera \& Navarrete, 2013, p. 7). A continuación se presentará parte de las entrañas de la UABJO, el sufrimiento de sus actores institucionales y las secuelas que se desencadenan en el marco de dicho fenómeno.

\section{Sufrimiento como sombra de la violencia}

Una vez más, con fundamento en Velázquez (2011), en este apartado se muestra la violencia, el sufrimiento y sus secuelas, padecidas por los actores institucionales dentro de la UABJO. En cuanto al sufrimiento psíquico, específicamente con referencia a lo que el sujeto siente, la francesa Blanchard (2009) analizó el malestar entre los profesores y estudiantes de su país. La autora muestra cómo puede ser desgastante otorgar parte de sí al otro y, en ocasiones, doloroso aceptar la falta de reconocimiento por parte del estudiante. Este trabajo de investigación fue un poco más allá de lo que Blanchard (2009) menciona.

En la UABJO se encontró a un exdirector de una facultad que incluyó en su gestión administrativa a un grupo de estudiantes recién egresados. El exdirector pensó que el haber sido su profesor garantizaba lealtad y obediencia de sus exalumnos, así que los colocó en puestos estratégicos para su administración, pero la exdirectora previa, quien también conocía a los recién egresados, intervino para controlar al equipo del director y la institución. Ante esta situación el entrevistado comentó: "Fue muy difícil obviamente porque ellos fueron mis alumnos. A la actual directora le asesoré la tesis de licenciatura. Fue una situación muy compleja" (J., comunicación personal, 12 de diciembre de 2013). Y dolorosa, según se deduce por el tono de voz y expresión no verbal del entrevistado; podemos detectar un sufrimiento latente por la traición que aún permanece oculto, negado y se infiere por sus expresiones.

Para profundizar en el sufrimiento social que genera la postmodernidad a los docentes, traemos a escena a Pérez (1999), quien afirma: "La cultura docente de final de siglo se nutre, en no escasa medida, de frustración, ansiedad, desorientación y cínico pragmatismo" (p. 176). La sociedad tiene desconcertado al docente, ante el incremento acelerado de demandas y una insuficiencia de los medios y recursos para responder a las mismas. Con respecto a las demandas de la postmodernidad, una profesora de asignatura de la UABJO comentó:

No tenemos laboratorios eficientes, no vamos a la par en tecnología como en muchas facultades de enfermería, carecemos de mucha infraestructura... Nos hemos quedado completamente rezagados y esto es preocupante porque la competencia en la profesión se ha dado en el estado a un paso agigantado. (E., comunicación personal, 13 de diciembre de 2013).

La angustia por cumplir con su tarea primaria es evidente, su preocupación por los recursos humanos que están egresando se entiende en su comentario: 
Esta gente que estoy formando con estos escasos recursos, ¿cómo va a competir cuando salgan al ámbito laboral? Se los van a comer, se los van a comer. Eso te provoca angustia cuando en realidad estás en tu papel de docente. (E., comunicación personal, 13 de diciembre de 2013).

La intranquilidad de la profesora es innegable debido a la infraestructura y escasez de material para impartir su cátedra, aunque también existe frustración laboral ante la exigüidad de los insumos indispensables para ejercer su labor profesional:

Con mi labor docente, no hay espacios específicos, usted tiene que irse a sentar a una banquita, buscar donde pueda estar haciendo el trabajo... No hay revistas actualizadas... Nuestra bibliografía no está actualizada como quisiéramos. Tenemos una sala de cómputo muy pequeñita. (E., comunicación personal, 13 de diciembre de 2013).

La profesora expresa que para cumplir eficientemente con la tarea primaria que marcan las demandas de la postmodernidad, la institución no está cumpliendo con su parte, a pesar de ser una facultad que cuenta con más de 133 años de historia, según lo constata la placa conmemorativa a su centenario que se encuentra a la entrada de la UABJO.

En relación con el sufrimiento profesional, según Remedi (2006), muchos investigadores del Sistema Nacional de Investigadores (SNI), que también tienen entre sus funciones la docencia, "serán alcanzados por el síndrome de burnout pagando con su cuerpo o con su psiquis lo que no se pudo elaborar en otro espacio, en otra escena" (p.87). Resulta pertinente mencionar que, según Herrera (2005), históricamente el término burnout fue introducido por Freudenberger en 1974 para referirse al fenómeno que había observado en sus compañeros de trabajo y en sí mismo. Herrera (2005) y Remedi (2006) nos ayudan a sustentar que las exigencias de los organismos reguladores violentan a los docentes al grado de enfermarlos.

En la UABJO, los docentes no son ajenos a estas exigencias, principalmente por los manejos poco confiables de la misma universidad en los procesos de evaluación docente y el otorgamiento de estímulos económicos. Durante el trabajo de campo, se pudo constatar que los Profesores de Tiempo Completo (PTC) se encontraban armando sus carpetas para enviarlas a las comisiones dictaminadoras de sus facultades, y éstas a su vez las remitirían a la Comisión Evaluadora de la universidad, encargada de estimar el desempeño docente durante el año. Los docentes emplean días para acreditar sus actividades mediante evidencias físicas como constancias de docencia, actas de calificaciones, antologías, apuntes, constancias como ponentes en congresos, fotos, entre otros. Los PTC cuentan que el año pasado, los estímulos se otorgaron a los amigos del grupo que ostenta el poder, lo cual generó mucha molestia, frustración e impotencia entre los profesores.

En cuanto a la violencia institucional, traemos a escena las investigaciones que se han venido desarrollando en Argentina (Fernández, 1996) y México (Herrera, 2009; Herrera \& Na- 
varrete, 2013; Sieglin, 2012). Las investigaciones develan las condiciones de trabajo de la élite académica, así como la marginación, estigmatización, tratos groseros, acusaciones injustas, amenazas por parte de los superiores o compañeros de trabajo. De igual manera, en esta investigación se ha detectado la política como factor intenso de sufrimiento. A un entrevistado se le preguntó: ¿Te tienes que meter en la política?, a lo cual respondió:

Sí, es muy difícil abstraerte. Hay casos de compañeros que dicen: "Yo no me meto, yo vengo a dar mis clases, yo hago investigación", pero en el camino, por diferentes circunstancias, terminas enfrascado en una situación de orden político... hay una lucha de poder muy viva. (J., comunicación personal, 12 de diciembre de 2013).

Los profesores tienen que entrar al juego de la política si quieren subsistir en la institución: "Aquí no son las cuatro funciones esenciales del Profesor de Tiempo Completo: tutorial, docencia, investigación y gestión. Son cinco, ¡vida política! Si estás un buen tiempo, llevas esa dinámica" ( $\mathrm{J}$., comunicación personal, 12 de diciembre de 2013). Es decir, en el transcurso del día, los profesores tienen que dedicar una parte de su tiempo a crear relaciones políticas con los diversos grupos que convergen en la institución. Si algún profesor se aísla, los lobos lo devoran como Hobbes (2006/1651) sostiene: el hombre es el lobo del hombre. Para sustentar el argumento, se preguntó al entrevistado: ¿Has visto que hayan reventado a alguien políticamente?, a lo cual respondió:
Sí. La tendencia es: No estás de acuerdo, entonces te limito, pero si no solamente no estás de acuerdo conmigo y empiezas a organizar, a hacer otras cosas, entonces puede presentarse una cuestión de choque. De repente, como no estoy de acuerdo y estás atacando, entonces muevo a los alumnos para que me apoyen. La lucha de poder es muy fuerte en la universidad. (J., comunicación personal, 12 de diciembre de 2013).

En esa lucha por el poder juegan los diferentes actores institucionales con su grupo respectivo, incluyendo a los alumnos, quienes son el botín que puede inclinar la balanza a favor de quien mejor pueda controlarlos. Por tal situación, los directivos en turno cuidan en exceso la asignación de los grupos y limitan al máximo el contacto del grupo opositor con los estudiantes. Cabe destacar que en las elecciones para dirigir las diversas facultades, todos los votos cuentan por igual, así que quien controla a los estudiantes, será quien dirija la institución. Los estudiantes son el trofeo y la llave para entrar a la dirección y controlar la facultad, aunque también los estudiantes pueden colocar a sus dirigentes.

Como se pudo demostrar en voz de los sujetos de análisis, las cuatro áreas de sufrimiento están presentes en la UABJO. Para sostener los argumentos de los entrevistados, en la encuesta se cuestionó a otros profesores e investigadores sobre los factores internos de la institución. La figura 4 muestra los resultados obtenidos acerca de la vida interna de la universidad y los vínculos entre los sujetos de análisis. 


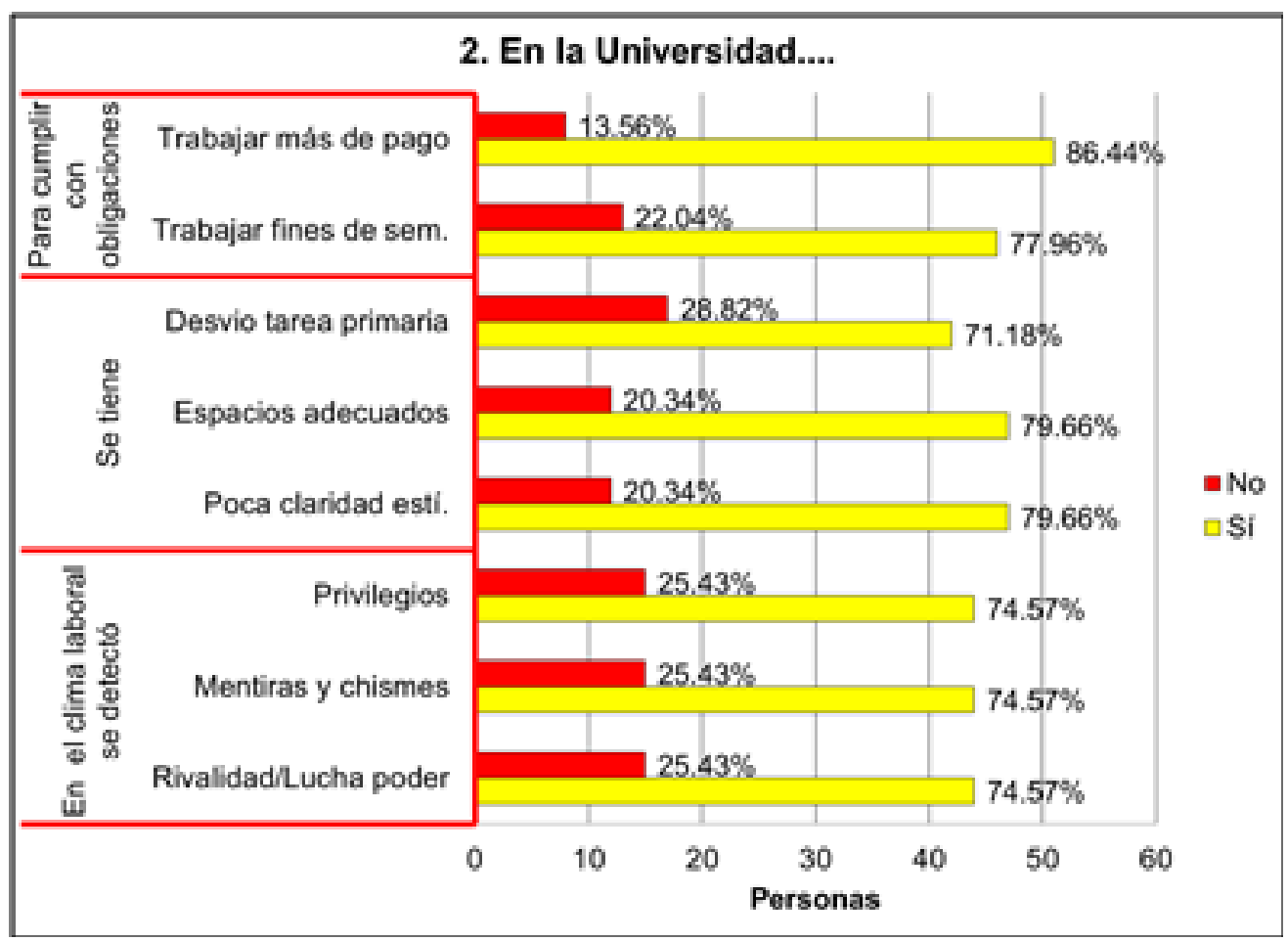

Figura 4. Resultados sobre la vida interna de la universidad y los vínculos entre los sujetos de análisis.

La figura 4 está dividida en tres secciones: la primera cuestionó a los docentes e investigadores sobre las obligaciones de su trabajo; la segunda parte se encaminó hacia las cuestiones administrativas de la UABJO; y la última sección se enfocó en el clima laboral y sus repercusiones en los docentes e investigadores. Resulta importante resaltar en la figura 4 que los sujetos de análisis manifestaron un $77.96 \%$ que necesitan trabajar más de su jornada laboral, asimismo, perciben que trabajan más de lo que les pagan en $86.44 \%$. En cuanto a las cuestiones administrativas, los encuestados señalaron en $71.18 \%$ que la UABJO desvía su tarea primaria, así como un $79.66 \%$ advirtió que no tienen espacios adecuados para el desarrollo de sus actividades cotidianas y $79.66 \%$ indicó que hay poca claridad en la asignación y transparencia de estímulos. El tercer grupo de preguntas enfocado al clima laboral detectó que existe una lucha y rivalidad por el poder, la cual está marcada por mentiras-chismes, además se privilegian a aquellos amigos que están con el grupo que controla la facultad. En los tres rubros, $74.57 \%$ sujetos coincidieron en sus respuestas.

\section{Estado biopsicosocial: huella y secuelas de la} violencia y sufrimiento

Como puede apreciarse, en la vida cotidiana de la UABJO se sufre por múltiples causas endémicas a la cotidianidad de la institución. El análisis de la información del trabajo empírico de la presente investigación concuerda con Herrera (2009), quien dice: 
Las instituciones educativas son un encuentro de cuatro grupos y culturas (local, institucional, estudiantil y docente), son lugares donde interactúan diversos sujetos institucionales con sus grupos de adhesión. Cada grupo lucha por sus beneficios, cada grupo tiene sus códigos de ética y dentro de cada grupo sus miembros se cuidan y protegen de los otros grupos. Es decir, firman el contrato narcisista y pacto de negación. (p. 26).

Estas dinámicas institucionales generan violencia de estados alarmantes en las universidades, y sabemos que cuando hay violencia alguien sufre. El sufrimiento es sombra e inherente a la violencia, en cualquier acto violento hay por lo menos una víctima. Ahora bien, el sujeto que recibe la violencia es un ser biológico, psicológico y social que al ser víctima altera de forma natural su estado biopsicosocial. Las evidencias presentadas hasta aquí demuestran que algunos docentes e investigadores han sido alcanzados por la violencia externa e interna que se vive en el estado de Oaxaca e institución educativa y como consecuencia han alterado su estado biopsicosocial. En algunos lugares de la UABJO existe acoso laboral como el que nos presenta Martín (2008) en su libro autobiográfico.

En cuanto a la parte social, una profesora de asignatura comentó que por los álgidos problemas que tienen con los grupos opositores, han tenido que dormir en la facultad por semanas para evitar que tomen la dirección. En dicho contexto, la profesora le pidió a su hija adolescente vivir temporalmente con su abuela debido a las amenazas que había recibido. En cuanto a la parte psicológica, un profesor (que prefirió quedar en el anonimato) comentó:

He visto mucho maestro quemado, se da mucho el burnout... De repente ves algunos compañeros que están en la neurosis... Algunos de repente se enferman de los nervios... A mí en específico neurosis y extrañamiento que es algo fuerte. Melancolía, depresión, ganas de no venir al trabajo. (A., comunicación personal, 12 de diciembre de 2013).

Dichos padecimientos se suman a los que se presentaron en al apartado previo: angustia y ansiedad por no poder cumplir con la tarea primaria de su labor docente. Este tipo de padecimientos psicológicos provoca que los docentes sean "muy pragmáticos, te vuelves muy duro, empiezas a ser insensible a ciertas cosas" (A., comunicación personal, 12 de diciembre de 2013).

Comúnmente la gente tiende a somatizar algunos trastornos psíquicos y desarrolla enfermedades médicas que imposibilitan a los sujetos por semanas. Un profesor de la UABJO comentó:

Empiezo a tener molestias en la espalda en dos o tres días la logro librar. Al siguiente año, cuando estuvo más tenso me paso dos semanas en cama. La ciática se manifiesta, no puedo parar el dolor de la pierna, no puedo ni moverla por la ciática y la región lumbar. (J., comunicación personal, 12 de diciembre de 2013).

Las cuestiones estresantes del trabajo llevaron al profesor a permanecer en cama por dos 
semanas, afortunadamente, después de recibir el apoyo de su esposa pudo reincorporarse a su labor. Además existen otros casos donde cotidianamente el cuerpo paga la factura por las cuestiones laborables. Otro profesor comentó: "Me despierto en la noche sin excepción, es una costumbre. Por lo menos una hora me estoy sin dormir... solamente puedo dormir bien en las vacaciones" (A., comunicación personal, 12 de diciembre de 2013).
Como se aprecia, la sombra y huella de la violencia es el sufrimiento y sus secuelas son impresionantes. Este trabajo es una pincelada del estado biológico, psicológico y social que viven algunos docentes e investigadores de la UABJO, por cierto, muy similar a lo que sucede en otras universidades autónomas de los diversos estados de país. La figura 5 muestra los resultados de la encuesta relacionados con los padecimientos biopsicosociales.

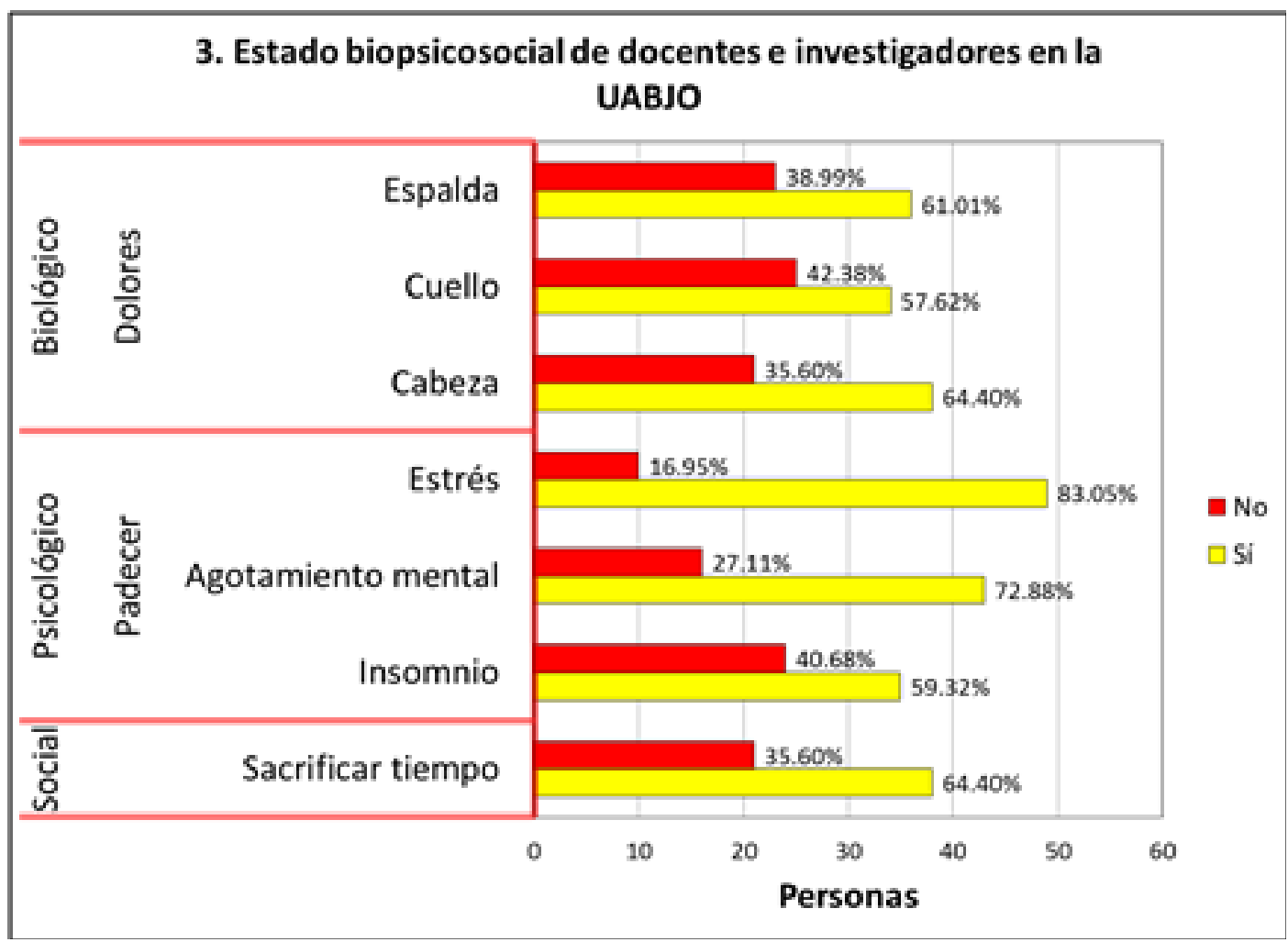

Figura 5. Resultados de la encuesta relacionados con los padecimientos biopsicosociales.

En la figura 5, se aprecia que $61.01 \%$ de los encuestados presenta dolores de espalda como consecuencia de sus actividades académicas e investigativas. Asimismo, un $57.62 \%$ y 64.40
$\%$ manifestaron tener dolores de cuello y cabeza respectivamente. Respecto a la parte psicológica, se puede detectar que tienen problemas de sueño, $59.32 \%$ padece de insomnio; sin lugar 
a dudas, esta patología alimenta otras más como el agotamiento mental que se manifestó en $72.88 \%$. Lo sorprendente de esta sección es que $83.05 \%$ manifestó estar estresado, el rubro más alto y peligroso. Esta misma figura permite observar que los sujetos de análisis han alterado las relaciones sociales en su vida, sin dejar de ver que aunado a sus padecimientos, $64.40 \%$ sacrifica tiempo con su familia por cumplir con las demandas de la institución.

\section{Conclusiones}

Como se pudo demostrar en el cuerpo del trabajo, la UABJO padece la violencia dentro y fuera de sus fronteras. En el exterior, los actores políticos alteran la vida cotidiana de la institución, ya sea intentando controlarla desde sus oficinas colocando a sus amigos del gremio en puestos directivos. Dentro de la universidad, los actores institucionales también contribuyen con la violencia interna, desde el sindicato, o dentro de su grupo de adhesión. Como lo demostramos, aquellos que intentan alejarse o aislarse de la política y grupos de poder son confrontados y devorados por el sistema. Estas variables sustentan el título del trabajo, cuando afirmamos que en la huella ecológica dejamos un rastro, así en nuestra cotidianidad, por comparación, de alguna u otra forma dejamos una huella de violencia. Es oportuno recordar que el sufrimiento es la sombra de la violencia, y donde hay violencia, alguien sufre. Coincidimos con Uribe (2011), la situación en México es cada vez peor, “la violencia será una variable que intervendrá cada vez más en la vida cotidiana de las personas y sus familias" (p.42).

El sufrimiento de los docentes e investigadores se pudo demostrar desde cuatro áreas (psíquica, social, profesional e institucional). Aunque es lógico y aceptable, resulta pertinente mencionar que no todos sufren por las mismas circunstancias; la encuesta permitió conocer que los porcentajes de padecimientos biopsicosociales son muy altos y si ignoramos la problemática de salud, ésta puede aumentar al paso de unos cuantos años. Desafortunadamente, en dichos casos el refrán de los oaxaqueños "Para todo mal mezcal y para todo bien también" está descontextualizado. Si se ignoran los padecimientos, éstos se incrementarán. Publicar y seguir investigando sobre el estado biológico, psicológico y social de docentes e investigadores para proponer soluciones al fenómeno social que se vive en diversas instituciones educativas del mundo, se vuelve indispensable.

\section{Referencias}

Ball, S. (1994). La micropolítica de la escuela. Hacia una teoría de la organización escolar. Barcelona: Paidós.

Bautista, E. (2008). Oaxaca: La construcción mediática del vandalismo y la normalidad. $E l$ cotidiano, 48(23), 37-44.

Blair, E. (2009) Aproximación teórica al concepto de violencia: Avatares de una definición. Política y Cultura, 32, 9-33.

Blanchard, C. (2009). Los docentes, entre placer y sufrimiento. México: Universidad Autónoma Metropolitana. 
Espasa Calpe. (1994). Diccionario de sinónimos y antónimos. Madrid: Espasa Calpe.

Fernández, L. (1996). Instituciones educativas. Dinámicas institucionales en situaciones críticas. Buenos Aires: Paidós.

Gampel, Y. (2006). Esos padres que viven a través de mí. La violencia de Estado y sus secuelas. Buenos Aires: Paidós.

Herrera, N. (2002). Descripción Organizacional de la Cabecera Municipal de Chimalhuacán (Tesina de licenciatura inédita). Universidad Autónoma Metropolitana, Distrito Federal, México.

Herrera, N. (2005). Estado de Burnout en los profesores de la Universidad del Valle de México. Revista Mundo UVM, 17, 48.

Herrera, N. (2008). La institución como objeto creador de sufrimiento. Revista Administración y Organizaciones, 10(20), 103-126.

Herrera, N. (2009). Historia, cultura, rol y sufrimiento. Análisis del Instituto de Educación Media Superior del Gobierno del Distrito Federal (Tesis doctoral inédita). Centro de Investigaciones y Estudios Avanzados del Instituto Politécnico Nacional, Distrito Federal, México.

Herrera, N., \& Navarrete, R. (agosto, 2013). Violencia y sufrimiento: Instituciones educativas como caja de resonancia de la sociedad. Trabajo presentado en el 1er. Congreso Internacional de Investigación Educativa de la RIE-UANL. Universidad Autónoma del Estado de Nuevo León, México.

Herrera, N. (2014). Novela del Instituto de Educación Media Superior. Revista Universi- dades [Unión de Universidades de América Latina y el Caribe (UDUAL), año LXV] 61, 70-83. ISSN: 0041-8935.

Herrera, N. (julio, 2014). Estado biológico, psicológico y social de docentes $e$ investigadores en Instituciones educativas. Trabajo presentado en el XXI International Conference on Learning. Nueva York, Estados Unidos.

Herrera, N. (septiembre, 2014). Investigaciones sobre el análisis de la violencia en México desde tres Universidades Públicas. Trabajo presentado en el XXX Congreso Latinoamericano de Psicoanálisis. Buenos Aires, Argentina.

Herrera, N. (octubre, 2014). Problemas Actuales de la Salud Mental en Universidades Mexicanas. Trabajo presentado en el II Congreso Internacional de Conflictividades. Medellín, Colombia.

Hobbes, T. (Ed.). (2006). Leviatán o la materia, forma y poder de una república, eclesiástica y civil. México: FCE.

Martín, Ch. (2008). Tiritando. Una historia de acoso laboral. Barcelona: Plataforma Editorial.

Moliner, M. (1998). Diccionario de uso del español. Madrid: Gredos.

Pérez, A. (1999). La cultura escolar en la sociedad neoliberal. Madrid: Morata.

Real Academia Española. (2001). Diccionario de la Lengua Española. Madrid: Espasa Calpe.

Remedi, E. (2006). Calidad y sufrimiento en la búsqueda desbocada de la excelencia. En M. 
Landesmann (Coord.), Instituciones educativas. Instituyendo disciplinas e identidades (pp. 61-88). México: Casa Juan Pablos.

Sieglin, V. (2012). El acoso laboral en Universidades Públicas en México. Incidencia y factores subyacentes. En F. Peña \& R. Valdivieso (Coords.), Tras las huellas del asedio grupal en México (pp. 21-41). México: Ediciones Eón.

Velázquez, L. (2011). Los estudiantes y la violencia. México: Eikon.

Uribe, J. (2011). Violencia y acoso en el trabajo. Mobbing. México: Manual Moderno.

Uribe, F. (2012). Consideraciones sobre la violencia. En M. Murueta \& M. Orozco (Eds.), Psicología de la violencia (Tomo I, pp. 5371). México: Editorial Amapsi.

Wackernagel, M., \& Rees, W. (2001). Nuestra huella ecológica. Reduciendo el impacto humano sobre la tierra. Santiago de Chile: LOM. 